\title{
Characterization of Sudan strains of Bacillus thuringiensis pathogenic to the larvae of the house mosquito Culex quinquefasciatus
}

\author{
Naiema E. Gorashi ${ }^{1}$, ${ }^{*}$ Hamadttu A. F. Elshafie ${ }^{2}$ Hamid A. Hamid ${ }^{2}$ and Dirar H. Dirar ${ }^{2}$ \\ ${ }^{1}$ Environment and Natural Resources Research Institute, National Centre for Research, \\ Khartoum, Sudan \\ ${ }^{2}$ Faculty of Agriculture, University of Khartoum, Shambat, Sudan \\ "Corresponding author, e-mail: elshafie62@yahoo.com
}

\begin{abstract}
Mosquitoes, as blood sucking insects and vectors for several serious human diseases, continue to be one of the major threats to public health, comfort and economic growth in the Sudan and many other countries. Dengue, yellow fever, and filariasis in addition to malaria are all transmitted by mosquitoes; this pest is controlled using chemical pesticides. The increasing concern about the environment and the hazards resulting from the sole reliance on pesticides and the acquired resistance to one or multiple insecticides forced scientist to seek for safer efficient alternatives or supplements for the chemical pesticides. Bacillus thuringiensis is considered to be one of the important microbial control agents capable of producing insecticidal proteins with specific pathogenicity. In this study, different samples were obtained from soils collected from different locations in Sudan and from stored products dust and dead insects, in addition to mosquito rearing bonds, with the objective of isolating entomopathogenic Bacillus thuringiensis strains. Thirty nine strains were isolated and identified morphologically and biochemically and their toxicity to the house mosquito Culex quinquefasciatus second and third instar larvae was evaluated. The larvae of the house mosquito were introduced to sterile distilled water treated with $500 \mathrm{ppm}$ concentration from each isolate. Significant differences existed between the isolates in their toxicity 42 hours post treatment, where mortality percentages ranged from $25 \%$ to $95 \%$ compared to $12.5 \%$ in the untreated control larvae. About $69 \%$ of the $39 \mathrm{Bt}$ isolates were found pathogenic (mortality $\geq 50 \%$ ) to the house mosquito larvae. Regression analysis revealed differences in the lethal times between the different isolates. The $L T_{50}$ values varied from 29.38 hours for isolate Om-5 to 131.9956 hours for isolate GF-18. The practical significance of these findings for management of mosquitoes is discussed. It is therefore concluded that Sudan environment is rich in Bacillus thuringiensis pathogenic to the house mosquito and 5 isolates resulted in cumulative mortality percentages above $80 \%$.
\end{abstract}

Key words: Culex quinquefasciatus, toxicity, Bacillus thuringiensis, mortality, isolates, microbial control, pathogenicity

\section{INTRODUCTION}

The desire for insect control increased significantly with the realization that insects can spread human disease. Vector-borne diseases including malaria, dengue, yellow fever, and filariasis remain severe public health problems in most of the countries in which they are endemic (Gratz and Jany, 1994) and they are all transmitted by mosquitoes. Filariasis or elephantiasis is known to be focally endemic in Sudan (Elsetouhy and Ramzy, 2003). Mosquitoes, as blood sucking insects and vectors for several serious human diseases, continue to be one of the major threats to public health, comfort and economic growth in the Sudan and many other countries. Out of the 26 Sudanese states, 12 are considered endemic areas for lymphatic filariasis particularly Darfur and Blue Nile States in central Sudan (El Setouhy and Ramzy, 2003).
Control efforts for the mosquitoes with concentrations of insecticides application has ultimately failed to check the progressive increase in the mosquito population. Among several reasons the resistance to almost all approved insecticides for use in vectors control is the utmost problem (Matambo et al., 2007). In addition, the chemical pesticides used to control them have created serious ecological problems (Moazami, 2002). These vectors were successfully controlled using DDT, which is considered as one of the persistent organic pollutants and it was allowed to be used only for the management of vector-borne diseases according to Stockholm convention (2001), and should be eliminated from use within 10 years and to implement suitable safer alternatives. The preference for biological pesticides over chemical pesticides has been widely accepted in different parts of the world (Saadoun et al., 2001). 
Bacillus thuringiensis $(\mathrm{Bt})$ is a group of gram positive, facultatively aerobic, motile, spore-forming bacteria (Okech and Odindo, 1995). It seems to be indigenous to many environments (Bernhard et al., 1977 and Bucher, 1981). Bt produces insecticidal toxins (WHO, 1882, Carlson, and Koslsto, 1993), which are environmentally safe and specific. The integrated approach using Bacillus thuringiensis-chemical pesticides could be viable alternative to the use of chemical pesticides alone. Many insecticides were found compatible with $\mathrm{Bt}$ having little or no effect on spore germination or cell multiplication (Benz, 1971and Morris, 1977). Bt activity was long considered to be restricted to Lepidoptera, until Hall et al. (1977) reported that many Bt powders kill mosquitoes.

Research in Sudan on this bioagent is limited and mainly done for academic purposes, so this study was done with the following objectives:

1. Isolation and characterization of entomopathogenic strains of Bacillus thuringiensis from local habitats (soils and insects).

2. Assessing the pathogenicity of the isolated strains against insect pests from different orders, namely; Diptera represented by the house mosquito, Culex quinquefaciatus Say

\section{MATERIALS AND METHODS:}

Collection of samples: Samples were collected from different locations in the Sudan. These samples included: agricultural lands (bare and green) infested store products. Collected samples were brought to the laboratory in plastic bags and kept at about $4^{\circ} \mathrm{C}$ in the refrigerator till used for bacterial isolation.

Isolation of spore-forming bacteria: Travers et al., 1987 method was used to isolate spore forming bacteria from the collected samples. The colonies from these plates were sub-cultured on the T3 medium for purification and then kept in slants and saved in the refrigerator for identification tests.

Microscopic examination: A smear of 24-48 hourold culture of each isolate was prepared on a clean microscopic slide and stained with gram stain. The smear was then examined microscopically under magnification (X100) to show the shape of the cell, the presence of the spores, their position and the dimensions of the cell in addition to the gram reaction. Schaeffer-Fulton method (Murray and Robinow, 1981) was used for endospore staining, where endospores appear as blue green structures while vegetative cells are brownish red.

Biochemical characteristics: Different biochemical tests were carried out to confirm the identity of the isolated gram positive bacilli as Bacillus thuringiensis, following; Barrow and Feltham, 1993; Collee et al. 1996; Claus and Berkeley, 1986 and Collins et al., 1995. These tests were catalase production, motility hydrogen sulfide production, anaerobic growth, production of indole, citrate utilization, starch utilization, gelatin hydrolysis, ability to grow at PH 5.7, decomposition of casein, growth in sodium chloride, maximum and minimum growth temperature, production of gas and acid from glucose, VogesProskauer test, aesculin hydrolysis and urease production.

Production of spores and crystals: Bt suspension was streaked on Nutrient Agar medium. The plates were then incubated at $37^{\circ} \mathrm{C}$ for 24 hours. Five loopfuls of this inoculum were transferred to $10 \mathrm{ml} \mathrm{T3}$ broth (Travers et al., 1987) in Erlenmeyer flasks. They were shaken for 9 days using electric shaker at speed of $60 \mathrm{rpm}$ until the spores and crystalline bodies were formed. After growth, $10 \mathrm{ml}$ were transferred to $10 \mathrm{ml}$ tubes and centrifuged at a speed of $3000 \mathrm{rpm}$ for 10 minutes. The supernatant broth was poured off and the pellets (spores and crystals) were washed three times with sterile distilled water (3000 rpm, 5 minutes each) and finally suspended in sterile distilled water (Carrozi et al., 1991).The final suspension was kept in the refrigerator for further studies, otherwise freezedried in the freeze-drier and kept in the refrigerator.

Detection of crystals: A smear from lysed cells (from section 3.21) was spread on a clean microscopic slide, air dried and heat fixed. The slide was filled with $5 \%$ aqueous solution of malachite green and placed over boiling water for 15 minutes during which the smear was not left to dry out from the dye. Thereafter, the slide was rinsed and stained for 5-6 minutes with gram safranine followed by washing and drying. The slides were examined microscopically (100Xs) to determine if crystalline inclusions were produced, where spores stain green/blue and crystals stain red (Bulla et al., 2004).

The house mosquito Culex quinquefasciatus Say: Larvae of Culex quinquefasciatus were collected from breeding ponds in Khartoum south, north of Elkalakla area, with the aid of the Malaria Control Department, Ministry of Health and transferred directly to the laboratory where they were classified into different stages. Larvae of the second and third instar stages were used for the bioassay.

Pathogenicity against Culex quinquefasciatus: For mosquitocidal assays, ten second and third instar larvae of the Culex quinquefasciatus were introduced 
Agric. Biol. J. N. Am., 2012, 3(7): 271-279

into a $20 \mathrm{~cm} \times 1.5 \mathrm{~cm}$ glass test tubes containing $5 \mathrm{ml}$ of the bacterial suspension in sterilized distilled water (Martin and Travers, 1989). The assay was performed in four replicates with a concentration of $500 \mathrm{ppm}$ spores and crystal mixture, prepared from the freeze dried product of the 39 isolates. Larvae in the control treatment were introduced into glass tubes containing water only. The tubes were randomly arranged in a test tube rack in the laboratory, where temperature was daily recorded. Mortality of the treated larvae was recorded after 18 and 42 hours.

Statistical analysis: One way analyses of variance in a completely randomized design were carried out to detect the significant differences between the different isolates against the test insects. Square root transformation was performed before the analysis, and Duncan's multiple range test was used for the comparison of means.

Minitab Software version 13.20 was used for probit analysis to determine the time-response of larvae treated with toxic isolates that caused mortality percentages greater than $50 \%$, during the time of the experiments.

\section{RESULTS}

The pathogenicity of the isolates of Bacillus thuringiensis was assessed against the mosquito Culex quinquefasciatus second and third instars larvae. Mortality was observed among larvae exposed to all isolates within 18 hours from the start of the experiment. However, mortality percentages were less than $50 \%$ (Fig.1a) but increased gradually within the next 24 hours (Fig. 1b).

The colour of the dead larvae exposed to the local Bacillus isolates was brown. At this point of time (18 hrs) $12.82 \%$ of the 39 local isolates tested, were found to be pathogenic to the Culex larvae. Significant differences $(P \geq 0.05)$ in the mortality caused by the different isolates and the larvae in the control were detected (Table 1). After 42 hours, approximately $34 \%$ of the Bacillus isolates were not toxic to the mosquito larvae as the mortality percentages were less than $50 \%$ (Fig. 1). The rest of the isolates $(66 \%)$ caused mortality percentages of more than $50 \%$. Eleven isolates $(28.2 \%)$ caused mortality percentages greater than $72 \%$. The highest mortality (95\%) was achieved when the larvae were exposed to isolate Om-5. Three of the isolates assessed (Po-42, Po-5 and Po-1) caused $90 \%$ mortality (Fig. 1). The least mortality, which was $25 \%$, was obtained by isolates Po-7, St-23 and $\mathrm{Kb}-26$, while only $12.5 \%$ mortality was obtained in the control.
Table 1: Mean $^{\dagger}$ mortality of Culex quinquefasciatus exposed to the isolates of Bacillus thuringiensis

\begin{tabular}{|l|l|c|}
\hline \multirow{2}{*}{ Isolate } & \multicolumn{2}{|c|}{ Mean mortality after exposure } \\
\cline { 2 - 3 } & $\mathbf{1 8}$ hours & 42 hours \\
\hline Wh-1 & 1.033 & 2.163 efghik \\
\hline Dn-4 & 1.219 & 2.188 defghik \\
\hline Om-4 & 0.777 & 2.118 efghik \\
\hline St-14 & 1.049 & 2.104 fghik \\
\hline Wh-5 & 1.048 & 1.957 ghikl \\
\hline Kb-29 & 1.139 & 1.925 hikl \\
\hline Gz-6 & 1.036 & 1.810 hiklm \\
\hline Kb-30 & 1.079 & $1.616 \mathrm{kklm}$ \\
\hline Om-6 & 1.160 & $1.616 \mathrm{iklm}$ \\
\hline Dn-1 & 1.136 & $1.595 \mathrm{iklm}$ \\
\hline Kb-26 & 1.137 & $1.549 \mathrm{klm}$ \\
\hline Po-41 & 1.136 & $1.366 \mathrm{Im}$ \\
\hline St-23 & 1.213 & $1.366 \mathrm{Im}$ \\
\hline Po-7 & 1.146 & $1.319 \mathrm{Im}$ \\
\hline Control & 0.606 & $1.035 \mathrm{~m}$ \\
\hline
\end{tabular}

${ }^{\dagger}$ Means of four replicates, square-root transformed; those followed by the same letters are not significantly different at $P \geq 0.05$ by Duncan's Multiple Range

Table 1. continued

\begin{tabular}{|c|c|c|}
\hline \multirow[t]{2}{*}{ Isolate } & \multicolumn{2}{|c|}{ Mean mortality after exposure } \\
\hline & 18hours & 42 hours \\
\hline Om-5 & 0.998 & $3.078 \mathrm{a}$ \\
\hline Po-1 & 0.994 & $2.997 \mathrm{ab}$ \\
\hline Po-5 & 0.944 & $2.997 \mathrm{abc}$ \\
\hline $\mathrm{Po}-42$ & 0.880 & $2.997 \mathrm{abc}$ \\
\hline $\mathrm{Ab}-1$ & 1.005 & $2.825 \mathrm{abcd}$ \\
\hline Sa-49 & 0.842 & 2.782 abcde \\
\hline Sd-2 & 0.891 & 2.737 abcdef \\
\hline St-2 & 1.034 & 2.737 abcdef \\
\hline Sa-8 & 0.940 & 2.733 abcdef \\
\hline Gf-18 & 0.998 & 2.721abcdef \\
\hline Kh-3 & 0.968 & 2.685abcdef \\
\hline $\mathrm{Ab}-3$ & 0.770 & 2.539 abcdefg \\
\hline Sd-3 & 0.777 & 2.486 bcdefgh \\
\hline St-13 & 1.016 & 2.445 bcdefgh \\
\hline Fh-6 & 1.202 & 2.437 bcdefgh \\
\hline St-6 & 1.126 & 2.435 bcdefgh \\
\hline Sa-2 & 0.755 & 2.396 bcdefgh \\
\hline Sh-14 & 0.694 & 2.386 cdefgh \\
\hline $\mathrm{Ab}-4$ & 1.209 & 2.386 cdefgh \\
\hline Po-2 & 1.048 & 2.332 defgh \\
\hline Sh-13 & 0.694 & 2.332 defgh \\
\hline Wh-4 & 0.678 & 2.301 defghi \\
\hline$A b-3$ & 0.959 & 2.279 defghi \\
\hline$A b-12$ & 1.079 & 2.279 defghi \\
\hline$A b-31$ & 1.016 & 2.265 defghi \\
\hline
\end{tabular}

†Means of four replicates, square-root transformed; those followed by the same letters are not significantly different at $P \geq 0.05$ by Duncan's Multiple Range 
The lowest mean mortality (1.319) after 42 hours was recorded for isolate Po-7, but still significantly different $(P \geq 0.05)$ from that recorded for the control where the mean mortality was (1.035), (Table 1). However, the highest mean mortality (3.078) was achieved by isolate Om-5. Dead pupae were also observed and were found unfolded as usual and their color was brown. Probit analysis was carried out to illustrate the biological response of the Culex quinquefasciatus larvae exposed to the toxic local isolates as indicated by mortality percentages equal to or greater than $50 \%$. The response observed with time when second and third instar larvae of Culex quinquefasciatus were subjected to 500 ppm of isolates Om-5, Sa-8 and Sn-3 was different as seen in Fig (2). While isolate Om-5 showed the highest potency, or the larvae were more susceptible to it, the rest of the isolates were closer to each other. Twenty nine hours were needed by isolate Om-5 to kill $50 \%$ of the treated larvae (Table 2). Isolates Sa-8 and Sn-3 were closer to each other in their potency or the susceptibility of the larvae towards them as 35 hours were enough to kill $50 \%$ of the larvae exposed to isolate Sn-3, additional four hour ware needed by isolate Sa-8 to cause the same mortality percentage. To achieve $90 \%$ mortality approximately two folds (1.8477 folds) of the time were required to kill $50 \%$ of the exposed larvae were needed by each isolate (Table 2 ).

Table 2: Time-response of $C$. quinquefasciatus exposed to the $B$. thuringiensis isolates $\mathrm{Om}-5, \mathrm{Sa}-8$ and $\mathrm{Sn}-3$ at 500 ppm

\begin{tabular}{|c|c|c|c|c|c|c|c|c|c|}
\hline \multirow[t]{2}{*}{ Isolate } & \multirow{2}{*}{\multicolumn{2}{|c|}{$\begin{array}{l}\text { Lethal times } \\
\text { (hours) }\end{array}$}} & \multicolumn{2}{|l|}{$\begin{array}{l}\text { Fiducial } \\
\text { (hours) }\end{array}$} & \multirow[t]{2}{*}{$\begin{array}{l}\text { Relative } \\
\text { potency }\end{array}$} & \multirow[t]{2}{*}{ Slope } & \multirow[t]{2}{*}{$D f$} & \multirow[t]{2}{*}{ Chi-Squar } & \multirow[t]{2}{*}{$\mathrm{Lt}_{90} / \mathrm{Lt}_{50}$} \\
\hline & & & Lower & Upper & & & & & \\
\hline \multirow[t]{3}{*}{ Sa-8 } & $\mathrm{Lt}_{10}$ & 21.2651 & 16.9016 & 25.3972 & \multirow{3}{*}{1.8477} & \multirow{3}{*}{6.449} & \multirow{3}{*}{2} & \multirow{3}{*}{2080} & \multirow{3}{*}{1.0} \\
\hline & $\mathrm{Lt}_{50}$ & 39.2929 & 33.3531 & 46.9652 & & & & & \\
\hline & Lt90 & 72.6039 & 59.1570 & 96.6284 & & & & & \\
\hline \multirow[t]{3}{*}{ Om-5 } & $\mathrm{Lt}_{10}$ & 15.9530 & 12.4850 & 19.1221 & \multirow{3}{*}{1.8477} & \multirow{3}{*}{6.449} & \multirow{3}{*}{2} & \multirow{3}{*}{2080} & \multirow{3}{*}{0.7502} \\
\hline & $\mathrm{Lt}_{50}$ & 29.4773 & 25.1518 & 34.6379 & & & & & \\
\hline & $\mathrm{Lt}_{90}$ & 54.4670 & 45.2033 & 70.3313 & & & & & \\
\hline \multirow[t]{3}{*}{ Sn-3 } & $\mathrm{Lt}_{10}$ & 19.4604 & 15.6832 & 22.9527 & \multirow{3}{*}{1.8477} & \multirow{3}{*}{6.449} & \multirow{3}{*}{$\begin{array}{l}2 \\
2\end{array}$} & \multirow{3}{*}{2080} & \multirow[t]{3}{*}{0.9151} \\
\hline & $\mathrm{Lt}_{50}$ & 35.9582 & 30.9470 & 42.4473 & & & & & \\
\hline & Lt90 $_{90}$ & 66.4422 & 54.5606 & 87.8593 & & & & & \\
\hline & & & & & & & & & \\
\hline
\end{tabular}


Agric. Biol. J. N. Am., 2012, 3(7): 271-279
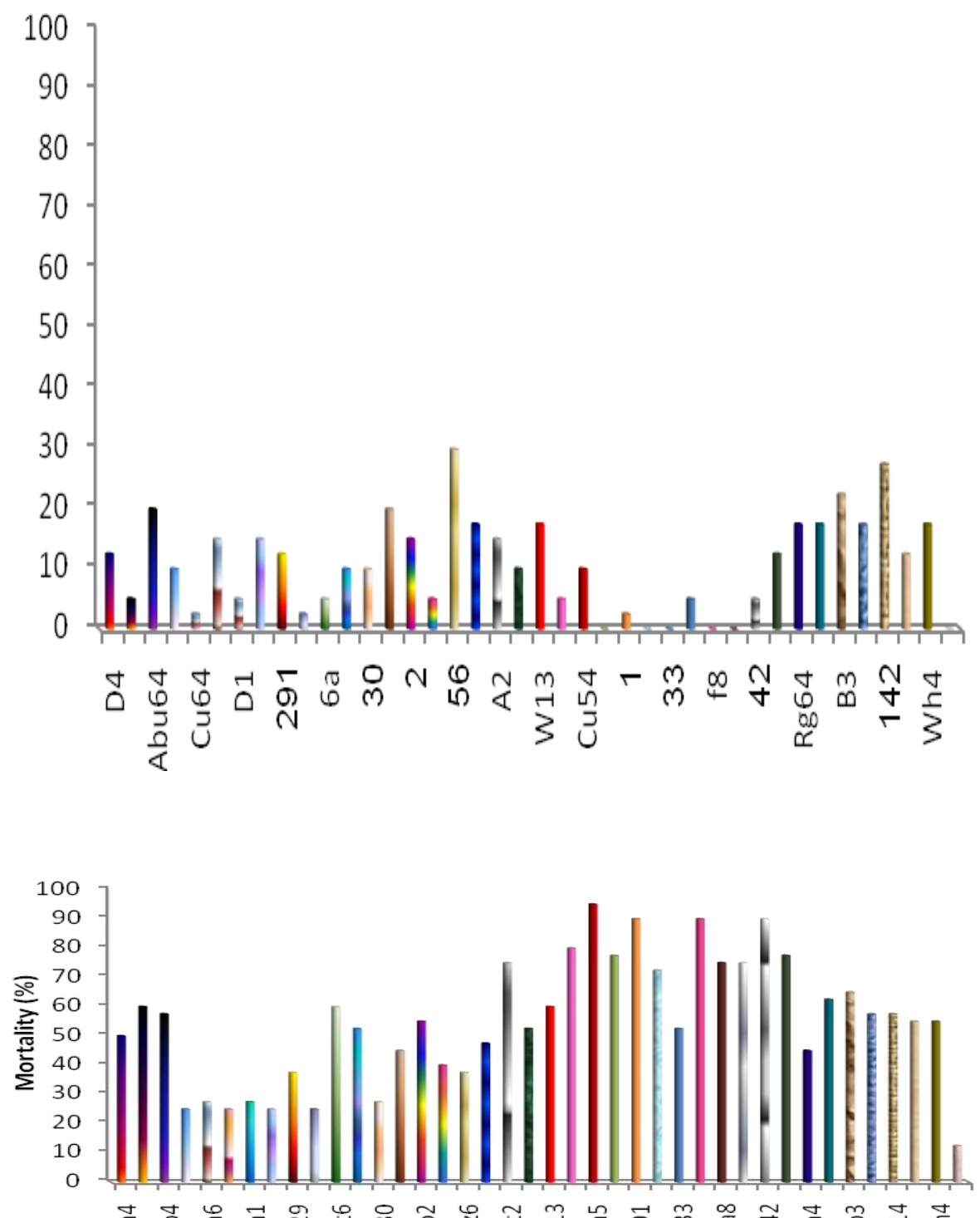

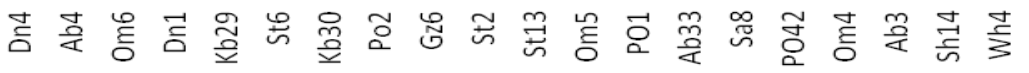

\begin{tabular}{|c|c|c|c|c|c|c|c|}
\hline \multirow[b]{2}{*}{ - Dn4 } & \multicolumn{7}{|c|}{ Local isolates } \\
\hline & - Fh6 & - Ab4 & St23 & $=\mathrm{Om} 6$ & $=\mathrm{Po} 7$ & - Dn1 & $=\mathrm{PO} 41$ \\
\hline - Kb29 & $\square \mathrm{Kb} 26$ & St6 & $=\mathrm{Ab} 12$ & Eb30 & St14 & $=\mathrm{Po} 2$ & $=$ Wh5 \\
\hline$\equiv \mathrm{Gz} 6$ & EWh1 & $=\mathrm{St} 2$ & Ab31 & - St13 & Ab1 & - Om5 & Gf18 \\
\hline PO1 & Kh3 & Ab33 & Po5 & - Sa8 & $\equiv \mathrm{Sn} 2$ & $\equiv \mathrm{PO} 42$ & - Sa49 \\
\hline - Om4 & - Sd3 & $\triangle \mathrm{Ab3}$ & Sa2 & : $\mathrm{Sh} 14$ & $\square$ Sh13 & Wh4 & $\square$ control \\
\hline
\end{tabular}

Fig. 1. Cumulative mortality (\%) of Culex quinquefasciatus larvae exposed to the isolates of Bacills thuringiensis; aafter 18 hours, b- after 42 hours. 
Agric. Biol. J. N. Am., 2012, 3(7): 271-279

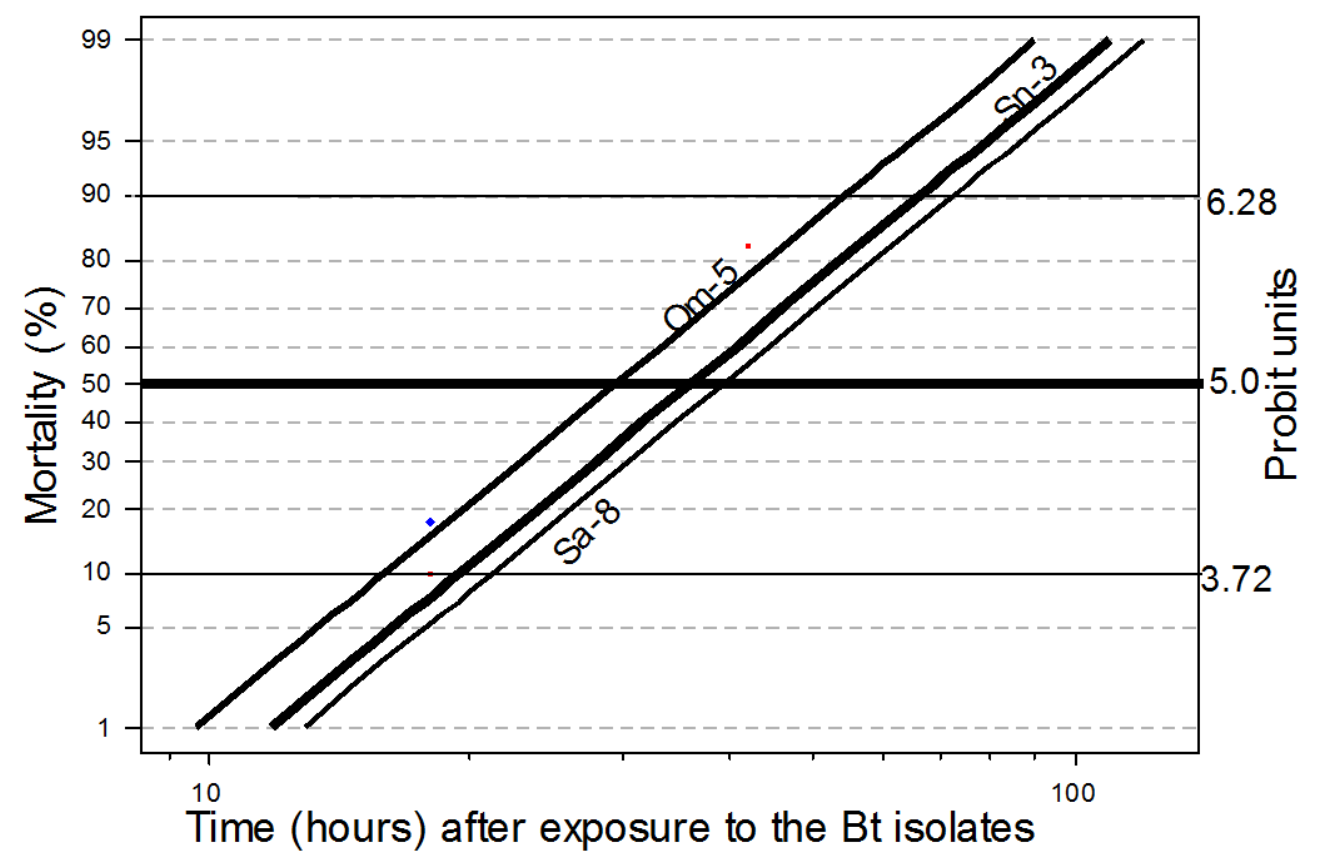

Fig 2: Time-response of $C$. quinquefasciatus exposed to the Bacillus thuringiensis isolates Sa-8, Om-5 and Sn-3 at 500 ppm.

\section{DISCUSSION}

Long term exposure to the modern synthetic insecticides has been associated with cancer, liver damage, immune-toxicity, birth defects and reproductive problems in humans and other animals (Kegley and Wise, 1998). The value of Bacillus

thuringiensis in controlling insects that transmit human diseases and destroy crops is well established. Accordingly, this study was proposed to isolate strains of Bacillus thuringiensis from Sudan local habitats and to test their pathogenicity against the larvae of the house mosquito.

The identity of the isolated bacteria as belonging to the genus Bacillus was confirmed morphologically and biochemically according to Sneath (1986). Isolates that were confirmed as Bacillus were subjected to further biochemical characterization tests (Claus and Berkeley, 1986; Phyllis et al., 1995) and resulted in 39 isolates closely resembling Bacillus thuringiensis. Previous workers were also able to isolate this entomopathogenic bacterium from different habitats in
Sudan including soil, insects and phylloplane (Omer, 1990; Elyass 2004).

The most important property of Bacillus thuringiensis is their specific insecticidal activity that is amenable to the production of bio-insecticides (Binh et al., 2005). Production of different sizes of crystals by the isolated strains was seen microscopically, which was also reported by other workers (Park et al., 1998 and Ahmed, 2004) and it might be due to genetic variability of the strains as they were grown under the same conditions. The isolated Bacillus thuringiensis could be grouped into different subspecies as indicated by the biochemical characteristics used to identify $\mathrm{Bt}$ subspecies. Also the differences in the type of crystal proteins produced by each isolate were shown microscopically.

About $66 \%$ of the isolates proved toxic to the mosquito larvae, mortality percentages of the treated larvae, in general increased with time. This could be attributed to the fact that the bacteria need time to be activated inside the midgut after being ingested. In addition, 
every hour the dose taken by the treated larvae was increased by ingesting from the treated water. Time was also needed for the subsequent events in the midgut starting from the ingestion, activation of the toxin, disruption of ion stability, and finally death of the treated insects (Lonc et al., 2003). Human resources are directly affected by mosquito species, so finding alternative control methods for this small, blood feeder, nuisance pest should be targeted for the coming few years. Mosquitoes were controlled mainly by insecticides including DDT which was allowed only for disease vector control and for a limited period of time as mentioned in Stockholm convention, 2001 (http://chm.pops.int/default.aspx). There are over 125 mosquito species with documented resistance to one or more insecticides (Brogdon and, McAllister, 1998). This resistance, in addition to the severe impact of mosquito and black fly-borne human diseases, creates considerable interest in identifying additional dipteran-active Bacillus toxins.

In this study $66.6 \%$ of the isolated Bacillus thuringiensis strains proved pathogenic to the Culex larvae after 42 hours of exposure to $500 \mathrm{ppm}$. This percentage superseded the percentage found by Hamza (2002) who found only 33\% of the Bacillus isolated from mosquito in Sudan were lethal to the mosquito larvae. In the present study $95 \%$ mortality was achieved in less than 48 hours, while in a study conducted by Hamza (2002), 80-100\% mortality was achieved by Sudan isolates after 48 hours. This high percentage of toxic local Bt strains to Culex quinquefasciatus larvae $(66.6 \%)$ confirmed the observation that most of the isolated strains possessed spherical or oval-shaped insecticidal proteins. It is well known that the characteristic shape of the mosquitocidal crystals is the spherical-shaped crystals. Bacillus thuringiensis israelensis produces this type of crystals (Charles and de Barjac, 1982), to which Culex larvae are more susceptible (Boisvert, 2005). In our research the least mortality percentage recorded was $25 \%$ which was obtained by isolates $\mathrm{Kb}$ 26, St-23 and Po-41, compared to $12.5 \%$ in the control of untreated larvae. Dead pupae were also observed, and were seen unfolded as normal with their colour changed to brown. Lacy et al. (2004) reported that successful pupation of Culex quinquefasciatus was significantly delayed when exposed to $B$. thuringiensis.

The pathogenicity of the locally isolated strains was further investigated using the probit analysis that showed the potency of the different isolates. Lethal times required to kill $50 \%$ of the population when exposed to $500 \mathrm{ppm}$ of the local isolates were found in the range of 29 to 45 hours. The highest potency and the highest mortality percentage were recorded for isolate $\mathrm{Om}-5$, and the least for isolate $\mathrm{Ab}-33$. These values were comparable to those obtained by Elyass (2004), who isolated Bacillus thuringiensis from Sudan and she reported $\mathrm{LT}_{50}$ range against Anopheles mosquito of 20.0 to 68.3 hours. She also examined a reference strain which is Bacillus thuringiensis var. israelensis where the calculated $\mathrm{LT}_{50}$ was found to be only 16 hours.

Differences in potency, in general, could be attributed to the differences in susceptibility of the treated insects as reported by Misztel et al. (1996) who explained the connection between insect mortality and exposure time. This author reported that highly susceptible insects stopped feeding within 60 minutes and died within 1-7 hours after ingestion of the toxin, less susceptible ones ceased feeding after 3-4 hours, and died after 2-7 days, while slightly susceptible insects stopped feeding after 10-15 hours and died after 2-3 weeks.

It was observed that the isolate that showed the least $\mathrm{LT}_{50}$ for mosquito was obtained from Omdurman, while that that showed the least potency towards mosquito was isolated from Abu-hamad. This could be reasonable as the problem of mosquito is more prevalent in Khartoum State than in the Northern State. It is well known that bio-agents of any pest should be searched for where that pest continuously existed and more likely to be found as it will be accompanied with its full array of natural enemies. These Bt. Isolates could be used in the management of mosquitoes in urban as well as agricultural areas to reduce the reliance on and the amount of synthetic insecticides and hence saving of the environment. However, before a conclusion can be reached, the Bacillus thuringiensis isolated in this study needs further identification of the isolates to confirm their identity such as insecticidal crystal protein using protein gel electrophoresis. The detection of cry genes that encode the insecticidal activity using PCR, with specific primers and mapping the distribution of cry genes in the whole country should also be done.

\section{REFERENCES}

Ahmed, A. A. 2004. Isolation and Identification of Bacillus thuringiensis from Sudanese Soils and Studies on Factors Affecting its Growth and Sporulation. (Ph.D. Thesis), U. of $\mathrm{K}$.

Barrow, G. I. and R. K. A. Feltham.1993. Cown and Steel's Manual for the Identification of Medical Bacteria $3^{\text {rd }}$ 
edition Cambridge University Press.

Benz, G. 1971. Synergism of microorganisms and chemical insecticides. Pp. 327-355. In: Burges, H. D.; and Hussey, N. W. (eds). Microbial Control of Insects and Mites. Academic Pres. N. Y.

Bernhard, K.; P. Jarret; M. Meadows; J. Butt; E. J. Ellis; G. M. Roberts; S. Pauli; P. Rodgers and H. D. Burges. 1997. Natural isolates of Bacillus thuringiensis, worldwide distribution, characterization and activity against insect pests. J. Inverteb. Pathol. 70: 59-68.

Binh, N. D.; N. X. Canh; N. T. A. Nguyet; N. D. Tuan; P. K. Thuy; N. T. T. Hanh; S-I. Asano; and M. Ohba. 2005. Characterization of Bacillus thuringiensis Strains in the Vietnam Bacillus thuringiensis Collection. Pp. 126-130 In: J-C Côté; I. S Otvos; J-L Schwartz and C. Vincent (eds). $6^{\text {th }}$ Pacific Rim Conference on the Biotechnology of Bacillus thuringiensis and its Environmental Impact. Fairmont Empress Hotel, Victoria BC, Canada, Oct. 30Nov. 3, 2005.

Boisvert, M. 2005. Utilization of Bacillus thuringiensis var. israelensis (Bti)-based formulation for the biological control of mosquito in Canada. Pp. 87-93 In: J. L. Cote, I. S. Otvos, J. I. Schwartz, andC. Vincent (eds). $6^{\text {th }}$ Pacific Rim Con. Biotechnology of Bacillus thuringiensis and its Environmental Impacts. Fairmont Empress Hotel, Victoria, BC, Canada, Oct. 30- Nov. 3, 2005.

Brogdon, W. G. and JC. McAllister. 1998. Insecticides resistance and vector control. Emerging and Infect. Dis. 4: 605-613.

Bucher, G. E. 1981. Identification of Bacillus found in insects. p 7-33. In: Burges, H. (ed.). Microbial Control of Insect Pests and Plant Pathogens 1971-1981. Academic Press. New York. USA.

Bulla, Jr.; A. Lee; M. Candas. 2004. Formicidae (ant) control using Bacillus thuringiensis toxin. US Patent. The Board of Regents. The University of Texas System (Austin, TX). 6797490. http://WWW.freepatent online.com/6797490.html.

Carlson, C. R.; and A. B. Kolsto. 1993. A complete physical map of a Bacillus thuringiensis chromosome. J. Bacteriol. 175 (9): 1053-1060.

Carrozi, N. P.; V. C. Kramer; G. W. Warren; S. Evols; and M. G. Kozeil. 1991. Prediction of insecticidal activity of isolates of Bacillus thuringiensis strains by polymerase chain reaction product profiles. Appl. Environ. Microbiol. 57: 3057-3061. Tortora et al. 1998).

Charles, J.-F., and H. de Barjac. 1982. Sporulation et cristallogénèse de Bacillus thuringiensis var. israelensis en microscopie électronique. Ann. Inst. Pasteur Mic. 133:425-442 (Cited in Boisvert, 2005).

Claus, D., and R. C. W. Berkeley. 1986. Genus Bacillus Cohn, p. 1105-1139. In: P. H. A. Sneath, N. S. Mair, M. E. Sharpe, and J. G. Holt (eds), Bergey's Manual of
Systematic Bacteriology Vol. 2. The Williams \& Wilkins Co., Baltimore.

Collee, J. G.; R. S. Mites, and B. Watt. 1996. Tests for identification of bacteria. p 131-149. In: Collee G.; B. P. Marmion; A. G. Fraser; A. Simmons (eds). Mackie and McCartney Practical Medical Microbiology $14^{\text {th }}$ edition. Churchill-livingstone, London.

Collins, C. H.; P. M. Lyne and J. M. Granhe. 1995. Microbiological Methods $7^{\text {th }}$ edition. Heinmann Ltd, Linacre House, Jordan Hills. Oxford.

El Setouhy, M. and R.M.R. Ramzy. 2003. Lymphatic filariasis in the Eastern Mediterranean Region: current status and prospects for elimination. La Revue de Santé de la Méditerranée orientale. 9 (4): 534-541.

Elyass, M. E. 2004. Biochemical, Serological and Entomopathogenic Characterization of Bacillus thuringiensis isolates from Various Habitats M.Sc. Thesis. U. of K.

Gratz, N. and Jany W. C. 1994. What Role for Insecticides in Vector Control Programs? Am. J. Trop. Med. Hyg., 50, (6): 11-20.

Hall, I.M., K.Y. Arakawa, H.T. Dulmage, and J.A. Correa. 1977. The pathogenicity of strains of Bacillus thuringiensis to larvae of Aedes and Culex mosquitoes. Mosq. News 37:246-251

Hamza, M. A. M. 2002. Studies on the Larvicidal Effects of Metabolites (Toxins) of Certain Bacillus species Against Anopheles arabiensis Mosquito Larvae. M. Sc. Thesis. U. of K.Murray and Robinow, 1981

Kegley, S. E., and L. J. Wise. 1998. Pesticides in Fruits and vegetables, Sausalito, CA. University Science Books.

Lacy, L. A.; J. Day; and M. Heitzman. 2004. Long term effects of Bacillus sphaericus on Culex quinfasciatus. J. Inverteb. Pathol. 49 (1): 116-123.

Lonc, E.; J Kucinska, and K. Ryzanicz. 2003. Comparative delta-endotoxin of Bacillus thuringiensis against mosquito vectors (Aedes aegypti and Culex pipiens). Acta Microbiol. Polonica. 52, (3): 293-300.

Martin, P. A. W.; and R. S. Travers. 1989. Worldwide abundance and distribution of Bacillus thuringiensis isolates. Appl. Environ. Microbiol., 55. 2437-2442.

Matambo, T.S.; Abdalla, H.; Brooke, B.D.; Koekemoer, L.L.; Mnzava, A.; Hunt, R.H., and Coetzee, M. 2007. Insecticide resistance in the malarial mosquito Anopheles arabiensis and association with the $\mathrm{kdr}$ mutation. Medical and Veterinary Entomology, 21, (1): 97-102.

Misztel, L.; W. G. Musial, and J. Augustyniak. 1996. Insecticidal toxins of Bacillus thuringiensis. Post Mikrobiol. 25: 193-211. (cited in Lonc et al., 2003).

Moazami,N. 2002. Biopesticides production, In: 
Encyclopedia of Life Support Systems. UNESCO, EOLSS publishers. $52 \mathrm{pp}$.

Morris, O. N. 1977. Compatibility of 27 chemical insecticides with Bacillus thuringiensis var. kurstaki. Canad. Entomol. 109: 855-864.

Murray, R. G. and C. F. Robinow. 1981. Schaeffer Fulton method for staining endospores. p. 17-33. In: Gerhardt, P,; R, G. E. Murray; R. N. Castilow; E. W. Nester; W. A. Wood; N. R. Krieg and G. B. Phillips (eds). Manual of Methods for General Bacteriology. American Scociety for Microbiology.

Okech, M. A.; M. O, Odindo,. 1995. Bacillus thuringiensis: A microbial control agent. USAID/ AELGA/ICIPE Regional Grasshopper/ Locust Biocontrol Training Course, Nairobi, 1-6 October 1995.

Omer. S. M. 1990. Bacteria Naturally parasitising mosquitoes at Khartoum and the possible larvicidal agent. Ph.D. Thesis (U.K).

Park, H.-W.; B. Ge,; L. S. Bauer; B. A. Federici.1998. Optimization of Cry3A Yields in Bacillus thuringiensis by Use of Sporulation-Dependent Promoters in Combination with the STAB-SD mRNA Sequence. Appl. Environ. Microbiol. 64: 3932-3938.
Phyllis, A. W. M.; E. B. Haransky; R. S. Travers, and C. F. Reichelderfer. 1985. Rapid biochemical testing of large numbers of Bacillus thuringiensis isolates using agar dots. Biotechn. 3 (5): 386-392.

Saadoun, I.; F. Almonani; M. Obedidat; M. Meqgam and A. Elbetieha. 2001. Assessment of toxic potential of local Jordanian Bacillus thuringiensis strains on Drosophila melanogaster and Culex sp. (Diptera) J. of Appl. Microbiol. 90 (6): 866- 872.

Sneath, P. H. A. 1986. Endospore-forming gram positive Rods and Cocci. p. 1104-1105 In: Sneath, P. H. A.; Mour, N. S.; Sharpe, M. E. and Hoit, J. G. (eds). Bergy's Manual of Systematic Bacteriology, 8th edition. Vol. 2, William \& Wilkins. Baltimore.

Stockholm Convention on Persistent Organic Pollutants (POPs). 2001. http://chm.pops.int/default.aspx

Travers, R. S.; P. A. W. Martin; and C. Reichelderfer. 1987. Selective process for efficient isolation of soil Bacillus spp. Environ. Microbiol., 53 (6): 1263-1266.

WHO. 1982. Data Sheet on the Biological Control Agent Bacillus thuringiensis serotype $\mathrm{H}-14$ (de Barjac, 1978). WHO/VBC/79.50 and VBC/BCDS/ 79.01. 42 pp. 